\title{
A Study on the Multi-Agent Based Comprehensive Benefits Simulation Analysis and Synergistic Optimization Strategy of Distributed Energy in China
}

\author{
Xiaohua Song ${ }^{1,2}$, Mengdi Shu ${ }^{1, *}$, Yimeng Wei ${ }^{1}$ and Jinpeng Liu ${ }^{1,2, *}$ \\ 1 School of Economics and Management, North China Electric Power University, Beijing 102206, China; \\ sxh@ncepu.edu.cn (X.S.); 1182206245@ncepu.edu.cn (Y.W.) \\ 2 Beijing Key Laboratory of New Energy and Low-Carbon Development, North China Electric Power \\ University, Beijing 102206, China \\ * Correspondence: 1172206160@ncepu.edu.cn (M.S.); ljp@ncepu.edu.cn (J.L.)
}

Received: 17 October 2018; Accepted: 21 November 2018; Published: 23 November 2018

\begin{abstract}
With the economic and social development of China, the continuous growth of the energy demand is the trend for now and the future. As a consequence, distributed energy, especially distributed electricity power generation, has received more and more attention. Thus, the scale and utilization level of distributed energy has been continuously improved. However, due to the limitations of current technologies, resources, policies and other issues, the comprehensive benefits and synergy levels of energy sources need to be greatly enhanced. Based on the system dynamics model, this paper examines the factors affecting the comprehensive benefits of distributed energy in China, screens the key subjects, and using the literature review method, combined with the existing literature analysis, constructs a comprehensive benefit evaluation index system and evaluates the comprehensive benefits through case analysis. This paper also sorts out the distributed energy-related Chinese government policies from 2001 to 2017, and considers the scale of distributed energy development, then divides it into two development stages. The synergetic entropy is used to analyze the synergetic development degree of the two-stage distributed energy entities. The synergistic optimization strategy is proposed from the Chinese government side, power supply side, power grid side and user side, which provides theoretical methods and optimization suggestions for improving the comprehensive benefits of distributed energy and promoting sustainable development of energy.
\end{abstract}

Keywords: distributed energy; comprehensive benefits; multi-agent synergetic estimation; synergistic optimization strategy

\section{Introduction}

During the "13th Five-Year Plan" period and in the near future, China's economy will be in a "new normal stage" for a long term. In such circumstances, energy demand will continue to increase, and the energy supply and demand system will face prominent development problems. For instance, energy supply and demand presure continue loose, and the policy targets for energy conservation and emission reduction are continuously increasing, posing a risk to energy safety and stability. Meanwhile the system operation level has not met the requirements of marketization. The energy supply structure in China is still dominated by coal. In 2016, coal accounted for about two-thirds of the total electricity generation. In such case, innovating the development model and promoting the development of comprehensive energy sources are of great significance. 
Compared with the traditional centralized energy sources, distributed energy has significant characteristics such as large development potential, flexible production, cleanliness and efficiency, as well as low pollution. The Energy Development Revolution Innovation Action Plan (2016-2030) issued by the National Development and Reform Commission of the Chinese government and the Energy Bureau proposed the high technology development plan for new energy power generation, including large-scale wind power, high-efficiency solar energy, distributed energy, energy storage technology and other related technologies. Energy technology innovation is expected to enter a golden period. The 13th Five-Year Plan for Energy Development attaches great importance to the development of distributed energy, acceleration of the construction of distributed energy projects, optimization of the solar energy development plan, and especially prioritization of the development of distributed photovoltaic power generation. With the support of the government policy, China's distributed energy development is continuously accelerating, with distributed photovoltaic power generation and biomass power generation being the most significant aspects. According to data from the China Foresight Industry Research Institute, the installed capacity of China's distributed photovoltaic power generation will double in 2017 compared with 2016. At the same time, the sustainable development goal of energy proposed by the international community provides a good opportunity for the development of distributed energy. Thus, distributed energy has great potential for development in the future.

However, despite, the fact the scale of distributed energy development has been expanding, in recent years, it is still in the initial and exploratory stage and the comprehensive benefits of distributed energy and the coordination between various entities desperately need to be enhanced. As a complex system, the entities of a distributed energy system not only include itself, but also large power grid cooproations, governments, markets and other entities have an important impact on its development. Due to the different interests and institutional mechanisms, these various entities have not reached a state of synergetic development. For instance, the power generation of distributed energy projects is self-contained, which affects the interests of power grid companies to a certain extent. The inactivity of power grid companies is inevitable, which restricts the improvement and further development of the comprehensive benefits of distributed energy system. Therefore, improving the multi-agent coordination of distributed energy is of far-reaching strategic significance for enhancing the efficiency and comprehensive benefit of energy utilization, and also promote building a safe, high-quality, economical and environmentally protective energy system, and contribute to achieving the goal of sustainable energy development proposed by the United Nations. Based on the aforementioned issues, analyzing the impact mechanism of distributed energy's comprehensive benefits and the degree of synergy between the main bodies, then discovering existing problems, exploring the potential benefit improvement potential, and optimizing multi-agent synergistic development mechanisms, are key subjects to enhance the comprehensive utilization benefits of distributed energy resources and promote large-scale investment in the distributed energy industry. At the same time, it is conducive to build a conservation-oriented society and accelerate the transformation of the energy structure.

\section{Literature Review and Research Methods}

\subsection{Literature Review}

With the growth of the total energy demand and the aim of reducing carbon dioxide emissions around the the globe, clean energy and renewable energy have attracted worldwide attention. Distributed energy systems have broadly developed prospects and great development potential due to their huge economic and environmental benefits [1-3]. Moreover, distributed energy systems have been studied in many countries as eco-friendly power systems that provide high quality power [4]. However, the development of distributed energy started late in China and still faces many difficulties. [5]. The references of this paper contain the research work on distributed energy at home and abroad that involves comprehensive benefits analysis and technical path optimization of the present situation. 
In terms of the comprehensive benefits, most of the current studies are on the economic benefits and cost-benefit analysis, and there is less discussion about comprehensive benefits analysis of distributed energy. Serrano, Omu and other scholars conducted a cost-benefit analysis of distributed energy installed at a specific location [6,7]. Inamori, Zhang et al. proposed an evaluation model for the cost-benefit analysis of distributed energy [8,9].In addition, Di Somma et al. proposed the promotion of the use of low-temperature energy from the perspective of fire efficiency, analyzed the contribution of each energy device in reducing energy costs and all inputs, and considered the economic factors affecting benefits by using the Pareto boundary [10].

In terms of the multi-agent synergistic optimization research, He et al. and other scholars analyzed how to obtain reasonable profits from the perspective of users and power supply companies to promote the healthy and orderly development of the distributed energy industry [11]. Zhang, and other scholars have proposed a new method of distributed generation and load coordination control in distribution systems, aiming to promote the synergetic development of distributed energy and distribution systems [12,13]. Reinders et al. evaluated pilot projects for smart grids in residential areas in The Netherlands and Austria to better support the coordinated evolution of various stakeholders [14]. Bale et al. used the methods of subject analysis and network modeling to extract the co-evolutionary factors of the multi-participants in the transportation system and power system, and make long-term predictions on the sustainable development of transportation systems and power systems [15].

\subsection{Research Methods}

The research content and research route of this paper are as follows: In the first section, this paper describes and analyzes the status quo of China's distributed energy development, and puts forward the significance of comprehensive benefits analysis and multi-agent synergistic optimization.

The second section introduces the research situation of the comprehensive benefits of distributed energy and multi-agent synergy. The models and methods used in each research part of this paper are also listed.

The third section builds a causal circuit diagram based on system dynamics, analyses the factors affecting the comprehensive benefits of distributed energy, and screens the main entities for explanations. According to the current research literature, this paper refined and the index to measure the comprehensive benefit sorted out, and the three-level index system of the comprehensive benefits is constructed accordingly. Then we take the demonstration project of Dong'ao Island as an example, to analyze its comprehensive benefits.

The fourth section reviews China's key policies for distributed energy development in recent years. and divides the development stages of distributed energy. Then it constructs a synergetic entropy, analyzes the synergy relationship of multi-agents between different stages, and proposes targeted strategies for its future development from the perspective of four key entities. The fifth section presents the conclusions. The technical flow of this paper is shown in the Figure 1. 


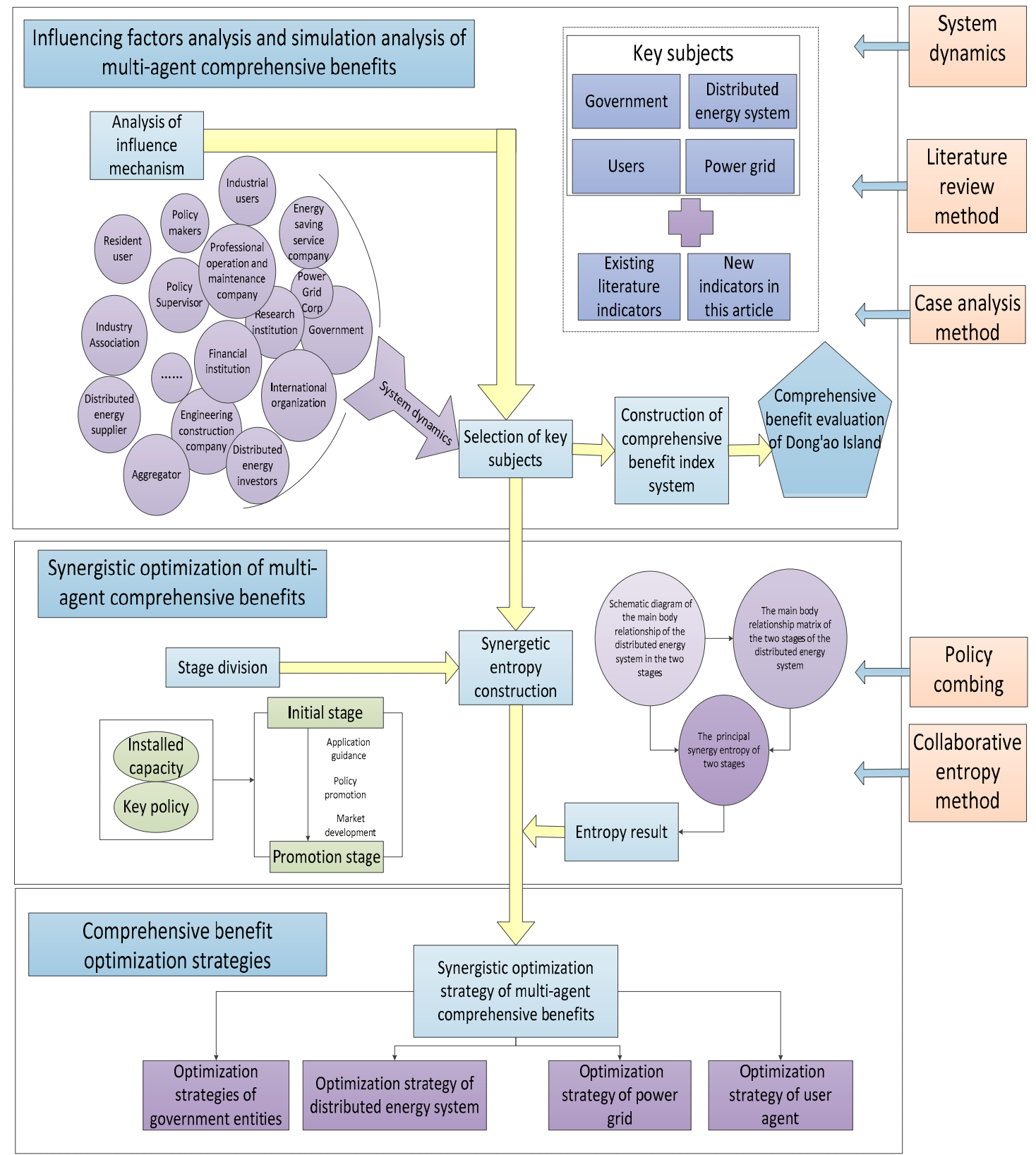

Figure 1. Schematic diagram of research content and research methods.

\section{Influencing Factors Analysis and Simulation Analysis of the Distributed Energy Multi-Agent Comprehensive Benefits Based on System Dynamics Method}

\subsection{Analysis of Factors Affecting Comprehensive Benefits}

The current development of distributed energy has already demonstrated certain comprehensive benefits. However, distributed energy systems involve different entities, including not only itself, but also large power grids, governments, users, markets, etc. Each entitiy is affected by many factors, and the interaction between each entity and the environment as well as other entities together affect the comprehensive benefits of the whole distributed energy system.

System dynamics reveals the main factors affecting system performance by revealing and analyzing the causal relationships between the internal components of the system, and then provides a basis for targeted improvement at a system operation level. The comprehensive benefits of distributed energy is a complex analysis system that needs to comprehensively consider elements regarding 
economic benefits, energy saving benefits, loss reduction benefits, reliability benefits, environmental benefits, and social benefits. By using system dynamics, the system can be scientifically divided into various subsystems, and the causal relationships between the system elements and the impact on the comprehensive benefits of distributed energy revealed. Based on the transmission mechanism among factors, the key factors affecting the comprehensive benefits of distributed energy can be revealed, which provides an important reference for multi-agent synergistic evaluation research. Therefore, system dynamics has applicability to the research of distributed energy comprehensive benefits transmission mechanism. Based on system dynamics analysis, it can clearly influence the main factors of distributed energy comprehensive benefits according to the direction of the conduction mechanism.

Based on the principle of system dynamics, this paper constructs a conduction mechanism diagram of the factors affecting the comprehensive benefits of distributed energy.

According to Figure 2, the interaction chain is concentrated around four main entities, including government, users, distributed energy suppliers and power grids. This paper focuses on those aforementioned entities and conduct a comprehensive benefits factor analysis.

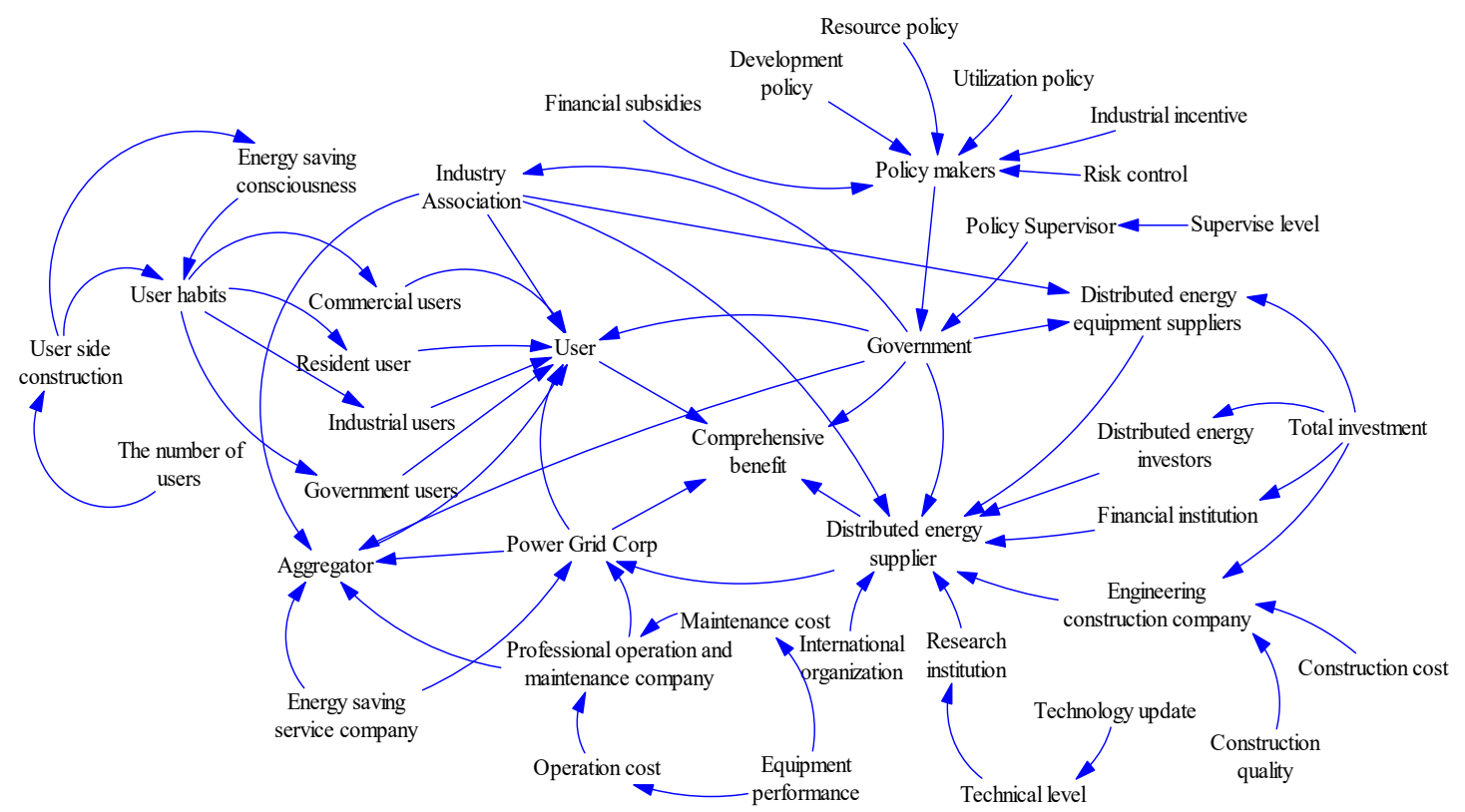

Figure 2. Conduction mechanism diagram of factors affecting the comprehensive benefits of distributed energy.

\section{(1) Government-side analysis}

It can be seen from the causal loop diagram that the influencing factors at the government level are mainly reflected in the policies issued by the government departments reponsible for distributed energy. Policy makers and policy supervisors jointly influence the promulgation and implementation of policies at different stages. Through development policies, resource policies, utilization polices and other aspects of policy support, as well as financial subsidies, industrial incentives and other positive measures formulated, policymakers affect the promotion of comprehensive benefits of the distributed energy in a certain level. At the same time, the supervision level of policy supervisors determines the implementation of distributed energy-related policies and the supervision and construction of distributed energy systems, and the comprehensive benefits will be improved when supervision is in place.

(2) Distributed energy systems analysis

The distributed energy system has the most direct impact on its comprehensive benefits, and it is deeply affected by other entities. The quality of the equipment supplied by the suppliers, the amount 
of funds provided by the investors and financial institutions, the construction cost of the construction companies and the quality of the projects, the support from government, the level of development of new technologies by scientific research institutions, the guidance from international organizations and trade associations affect the comprehensive benefits of distributed energy.

(3) Power grid company analysis

Distributed energy systems and power grids complement each other. The distributed energy system directly placed on the user side cooperates with the power grid to improve the reliability of the power supply. When the power of the distributed energy system is in short supply, power can be purchased from the main power grid. In the process of synergy between distributed energy systems and power grids, energy-saving service companies and professional operation and maintenance companies provide guarantees, theoretical and technical support for the integration of distributed energy systems, and affect its synergetic development, thereby affecting the improvement of its comprehensive benefits.

(4) User-side analysis

Users have a direct impact on the overall benefits of distributed energy. The user's energy consumption habits and energy-saving awareness are the key factors for selecting distributed energy generation, and the quantity reflects the situation that distributed energy replaces other energy sources. At the same time, the construction of the user terminal will directly affect the user's energy consumption convenience and energy consumption habits, thus affecting the energy efficiency and ultimately affecting the comprehensive benefits.

\subsection{Distributed Energy Comprehensive Benefits Evaluation and Case Simulation Analysis}

\subsubsection{Distributed Energy Comprehensive Benefits Index System}

This paper sorts out the indicators for measuring comprehensive benefits in the published literature, and divides the comprehensive benefits into six aspects: economy, energy saving, loss reduction, environment, reliability and society. The government side mainly involves environmental, social and economic benefits. The user side mainly involves reliability and energy saving benefits. The power grid company side mainly deals with loss reduction, environmental, reliability, economic and energy saving benefits, and the distributed energy side involves economic, energy saving, loss reduction, and reliability benefits.

In terms of the economic benefits, distributed energy shall be regarded as local peak shaving storage utility. Compared with large-scale energy storage, it not only saves economic costs but also reduces technical difficulty and has better economic benefits. Han, Dong, and other scholars measured the economic benefits from the initial investment and annual cost of the system [16,17]. Zeng used the net present value, cost-benefit ratio, and payback period to measure economic benefits [18]. He uses economic indicators and price risk indices to evaluate economic benefits [19]. Wu gave a comprehensive consideration of operating costs and pollution control costs [20]. This paper considers the comparison with conventional coal-fired power generation projects and sets the annual income increase index of the project.

In terms of the energy efficiency, renewable energy is often used in distributed energy sources, which can significantly reduce the consumption of fossil fuel and achieve energy conservation and emission reduction. Xie and other scholars use the energy-saving and emission-reduction investment costs of distributed energy units, as well as the value of fossil energy saved by conventional thermal power units, distributed energy supply equivalent energy and heat energy as a measure of energy efficiency [21]. This paper considers the ratio of renewable energy to fossil fuel energy in renewable energy units in distributed energy systems, and sets the energy replacement rate indicators.

In terms of the transmission loss reduction benefits, the energy in distributed systems can be locally consumed, reducing long-distance transportation, resulting in less electrical losses and promoting 
energy savings. Chen et al. used the benefits of loss reduction to measure the overall benefits [22]. Liang gave a cost-benefit analysis of micro-grids, concluding that the factors of loss reduction are the rate of loss, power generation, the number of distributed energy sources in the micro-grid [23].

In terms of the environmental benefits, distributed energy can adopt a "spontaneous use, surplus electricity online" consumption model to greatly reduce carbon dioxide emissions. Distributed energy technologies based on renewable energy can improve energy efficiency and increase the proportion of renewable energy structures. Zhang and other scholars used the emissions of major pollutants as a measure [24]. Zeng used the pollutant emission reduction and noise influence degree to calculate environmental benefits [25].

In terms of the reliability and efficiency, distributed energy can improve power supply reliability, power quality, and avoid losses caused by power outage losses and voltage drops. In the case of external power grid failures, distributed energy can be converted to independent operation mode, and continue to supply power to important loads, improving the reliability of power supply for important loads, and providing excellent power quality with other ancillary services. Mitra calculated various reliability indicators that affect the working state of distributed energy systems [26]; Gludpetch used the system average interruption frequency index, the system average interruption duration index and the unpowered energy as reliability indicators [27].

In terms of the social benefits, the advantages of distributed energy can bring benefits to society, such as economically and effectively solving the power supply issue in remote areas, achieving energy conservation and emission reduction, driving related technological progress and innovation, and stimulating employment in related industries. Tian used social saving efficiency, saving coal-fired efficiency, saving network loss benefits, reducing short-circuit current efficiency, and sustainable development benefits to optimize social resource allocation efficiency to measure social benefits [28]. This paper increases the technical update rate indicator and measures social benefits from the technical level.

According to the published literatures, after refining and processing, a three-level index system for distributed energy comprehensive benefits involving multiple entities is obtained and shown as Figure 3:

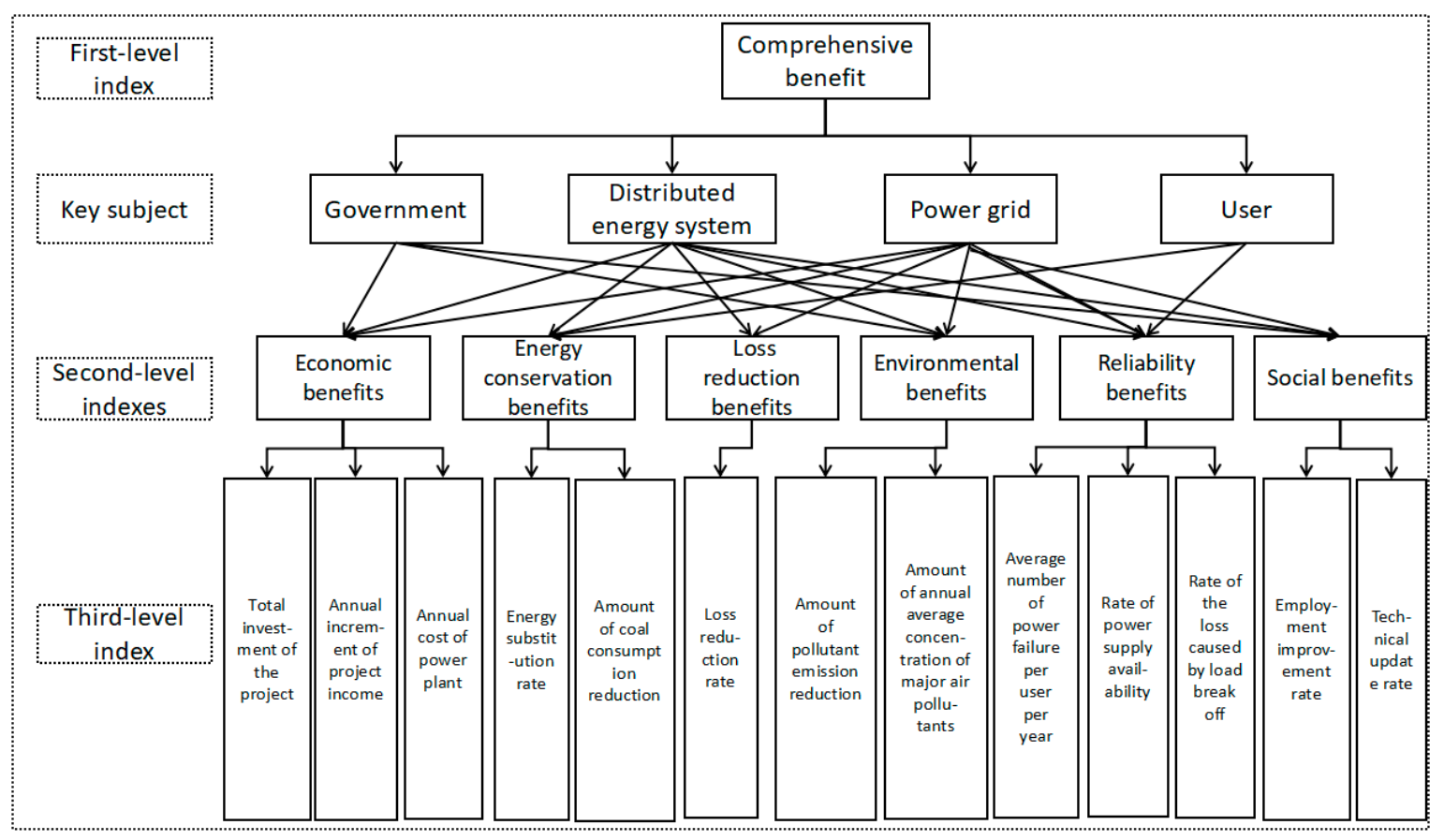

Figure 3. Multi-agent based distributed energy comprehensive benefits three-level indicator system. 


\subsubsection{Analysis of the Comprehensive Benefits of Typical Engineering Cases}

In this paper, the comprehensive benefits analysis is carried out with the example of Dongao Island Wind-Solar-Diesel-Battery(MW grade) multi-energy complementary demonstration project.

Dongao Island is located in the south-central part of the Wanshan Island in Guangdong Province, China. Due to the unique geographical and resource conditions of the island, it is more suitable for the construction of distributed energy systems. Dongao Island's wind \& solar \& desiel generator and smart storage micro-grid combines wind power generation, solar power generation, diesel generation unit and battery energy storage facilitiy. This paper compares the benefits of the distributed energy accessed to Dongao Island before and after. The specific benefits are as shown in Table 1.

Table 1. Dongao Island Comprehensive Benefits Analysis Table.

\begin{tabular}{|c|c|c|}
\hline Benefits & Before Accessing Distributed Energy & After Accessing Distributed Energy \\
\hline $\begin{array}{l}\text { Economic } \\
\text { Benefits }\end{array}$ & $\begin{array}{l}\text { The electricity cost for residents is } 2.9 \text { yuan } \\
\text { per degree. } \\
\text { The commercial electricity is } 3.24 \text { yuan } \\
\text { per degree. } \\
\text { The average annual loss of power plants is } \\
\text { about } 400,000 \text { yuan. }\end{array}$ & $\begin{array}{l}\text { The civilian use is } 2.6 \text { yuan per degree } \\
\text { (including subsidy } 0.8 \text { yuan). } \\
\text { The commercial price is } 3.74 \text { yuan per degree. } \\
\text { Under the synergy of the government, the } \\
\text { annual profit of the power station exceeds } \\
2 \text { million yuan. }\end{array}$ \\
\hline Energy Efficiency & $\begin{array}{l}\text { Diesel power generation, about } 2000 \text { tons of } \\
\text { oil for power generation per year. }\end{array}$ & $\begin{array}{l}\text { Under the synergy between the distributed } \\
\text { energy, the power grid and the government, } \\
\text { green energy replaces diesel power } \\
\text { generation, and the power generation } \\
\text { accounts for more than } 80 \% \text {, saving } \\
\text { traditional energy. }\end{array}$ \\
\hline $\begin{array}{l}\text { Loss Reduction } \\
\text { Benefits }\end{array}$ & $\begin{array}{c}\text { The transmission line is long and the line loss } \\
\text { is huge. }\end{array}$ & $\begin{array}{c}\text { Under the cooperation of the power grid and } \\
\text { the distributed energy, the loss of the } \\
\text { transmission and distribution network is } \\
\text { greatly reduced. }\end{array}$ \\
\hline $\begin{array}{l}\text { Environmental } \\
\text { Benefits }\end{array}$ & $\begin{array}{c}\text { Noise pollution, carbon dioxide, sulfur } \\
\text { dioxide and other emissions seriously pollute } \\
\text { the environment. }\end{array}$ & $\begin{array}{l}\text { Under the support of the government and the } \\
\text { power grid, the annual reduction of carbon } \\
\text { dioxide is nearly } 1500 \text { tons, sulfur dioxide is } \\
45 \text { tons, dust is } 40 \text { tons and clean water is } \\
6000 \text { tons. }\end{array}$ \\
\hline $\begin{array}{l}\text { Reliability } \\
\text { Benefits }\end{array}$ & $\begin{array}{l}\text { The minimum load in the off-season is } 20 \mathrm{~kW} \text {, } \\
\text { the maximum load in the tourist season is } 600 \\
\mathrm{~kW} \text {, the randomness of the load is very large, } \\
\text { the diesel engine failure rate is very high, the } \\
\text { voltage is very unstable. } \\
\text { There is a serious shortage of electricity in the } \\
\text { tourist season, and users often meet with } \\
\text { power failure. }\end{array}$ & $\begin{array}{l}\text { The voltage is stable, the reliability of power } \\
\text { consumption is greatly guaranteed. } \\
\text { The synergy between distributed energy and } \\
\text { users has been greatly improved. }\end{array}$ \\
\hline Social Benefits & $\begin{array}{c}\text { Lack of water and electricity, and residents' } \\
\text { lives are greatly affected. } \\
\text { Tourists are scarce and economically } \\
\text { undeveloped. }\end{array}$ & $\begin{array}{l}\text { Renewable energy has been developed, } \\
\text { power structure has been changed, energy } \\
\text { crisis has been prevented, and residential } \\
\text { electricity problems have been solved. } \\
\text { It has promoted the development of island } \\
\text { tourism and enhance local economic level. }\end{array}$ \\
\hline $\begin{array}{l}\text { Comprehensive } \\
\text { Benefits }\end{array}$ & $\begin{array}{l}\text { Low energy efficiency. } \\
\text { Poor comprehensive benefits. }\end{array}$ & $\begin{array}{c}\text { Higher energy efficiency. } \\
\text { Better comprehensive benefits. }\end{array}$ \\
\hline
\end{tabular}


Among the six benefits in Table 1, economic benefits, environmental benefits and energy saving benefits are the most significant and most intuitive. The improvement of the loss reduction benefits and reliability benefits also require the advancement of technology. Social benefits are more comprehensive and abstract, and affected by many external factors, so their the improvement may be slow and insignificant. Each entity has a two-way impact on the overall benefits of distributed energy. During the steady improvement of the comprehensive energy efficiency of the Dongao Island, the local government, in order to integrate it into the large power grid, cooperated with the power grid company, no longer offered any preferential treatment on the project land and policies, so the comprehensive benefits were reduced. The enhancement of the comprehensive benefits need to be further coordinated by the government, power grid, distributed energy and other main bodies.

\section{Research on Synergistic Optimization Strategy of Distributed Energy Comprehensive Benefits Based on Multi-agents}

In order to accurately measure the level of synergy and effectiveness of distributed energy systems, and through the synergy optimization between the subjects to further improve the overall benefits and achieve the goal of sustainable development of distributed energy resources, ensuring that user has access to affordable, reliable and sustainable modern energy, this study uses synergetic entropy to synergetic estimate distributed energy systems. Firstly, the relationship diagram of the distributed energy system is constructed as the research object. Secondly, based on the dissipation theory, the cooperative entropy index of distributed energy system is proposed, and the cooperative entropy calculation formula of distributed energy system is further established to comprehensively evaluate the evolution and the degree of synergy of distributed energy system.

The participating subjects and related relationships of distributed energy systems present different correlation characteristics and associated states at different stages of system development, and there are also hierarchical differences in the extent of driving factors. This study combines the relevant government work reports of power systems, important events of distributed energy power systems, national data and distributed energy power policies over the years to show the relationship, degree of association and type of association between the main components of distributed energy systems in the current stage.

\subsection{Division of Distributed Energy Development Stage Based on Policy Analysis and Development Scale Analysis}

In the 20 years of distributed energy development, the scale of China's distributed power generation has been gradually expanded under the support and guidance of relevant national policies. Natural gas distributed generation, solar photovoltaic power generation, biomass power generation, wind power generation and other related support policies have been issued. Figure 4 shows the key targeted policies for promoting distributed energy generation systems and the scale of distributed energy development represented by distributed photovoltaics and distributed biomass since 2000 . 


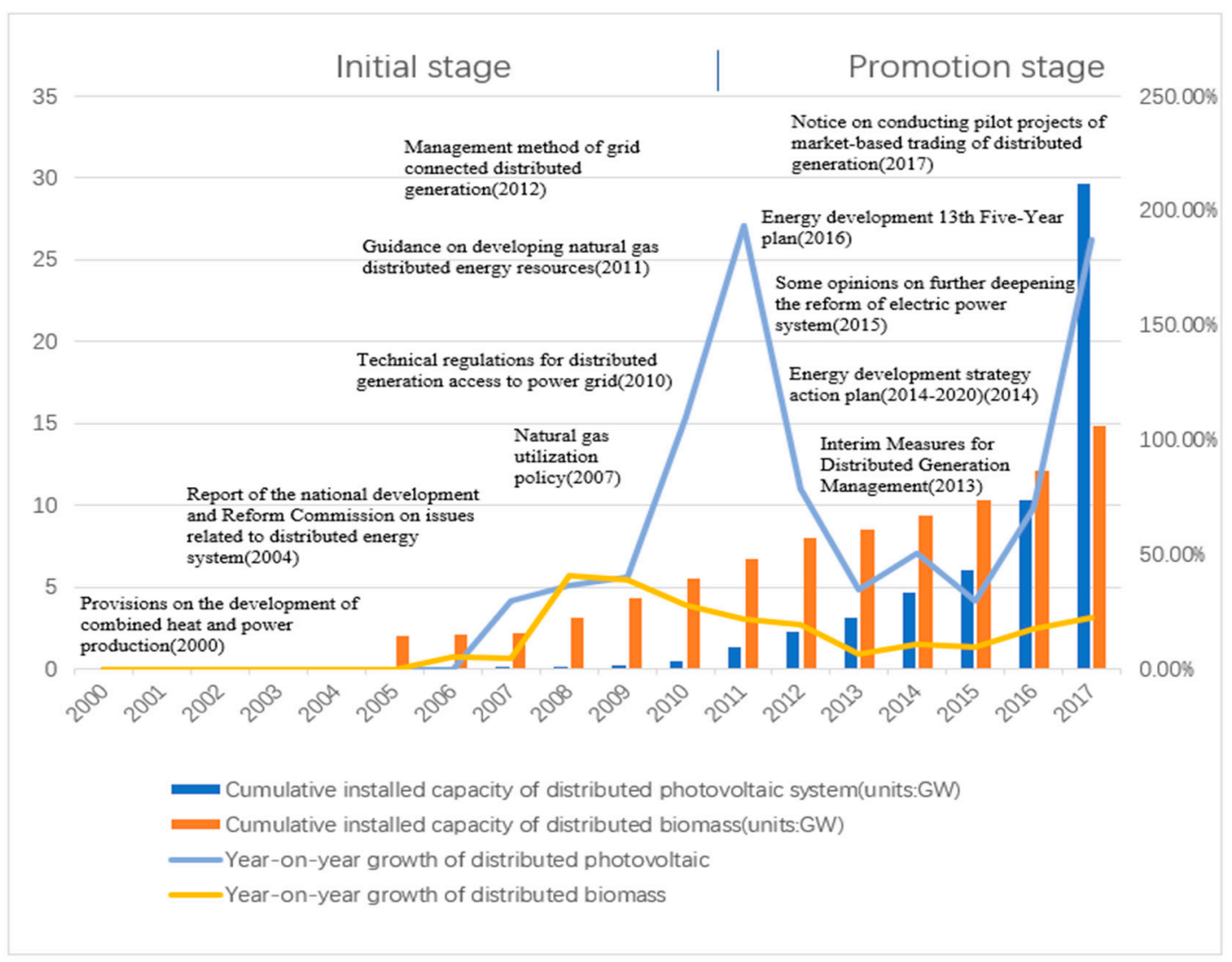

Figure 4. Distributed photovoltaic power generation, distributed biomass power generation cumulative installed capacity and year-on-year growth and key policy maps from 2000 to 2017.

On the basis of comprehensive consideration of the factors affecting the stage of China's distributed energy development, this paper divides the development time of China's distributed energy system from 2000 to 2017 according to the promulgation time of key policies and the analysis of development scale. The period from 2000 to 2011 is the initial stage, and from 2012 onwards as a promotion stage.

\subsubsection{Initial Stage (2000-2011)}

The initial stage is the preliminary period of distributed energy. At this stage, the term distributed energy officially appears in government documents. Most of the policies are macro-enhancement policies, and the scale of distributed energy installation is limited. During this period, a number of cogeneration projects have been initially explored, and distributed energy projects represented by natural gas-fueled distributed energy systems were gradually put into use in large cities. In 2004, the National Development and Reform Commission's Report of China on Issues Related to Distributed Energy Systems officially defined the concept of distributed energy. The pilot projects of distributed energy in economically developed areas have produced certain economic and social benefits, laying the foundation for the promotion and application of distributed energy systems into more expanded areas. However, the integration of distributed energy at this stage is still difficult, and the scale of distributed energy installation is only expanded to $10 \mathrm{GW}$, but the speed is relatively slow.

\subsubsection{Promotion Stage (2012-Present)}

The promotion phase is a period of substantial development of distributed energy. In this stage, policies are more targeted and the development speed of distributed energy is significantly accelerated. The policy intensity in this phase is correspondingly high. Since the "Twelfth Five-Year Plan", the 
development of China's distributed energy system has entered the promotion stage, and support policies have been introduced one after another, mainly involving natural gas distributed energy and distributed photovoltaics. Among them, the promulgation of the Interim Measures for Distributed Generation Management marks that China has begun to promote the development of distributed energy. In 2013, State Grid Corporation of China issued the "Opinions on Doing a Good Job of Distributed Power Grid-Connected Services" to legalize and order the grid. At this stage, there are plenty cases in which a number of individual users self-generated applications for grid connections. This resulted in the scale of installed capacity reaching a maximum of $187 \%$, and there is a tendency to continue to expand at this rate, with a considerable future potential.

Allowing distributed energy grid-connected is the milestone in the development process of distributed energy. However, the supporting measures involved in grid-connected are not perfect, and there are obstacles in the development of distributed energy, so as the economic benefits are not significant.

\subsection{Multi-Agent Synergistic Relationship Analysis of Distributed Energy Systems}

Based on the characteristics of distributed energy systems and existing research results, this paper extracts the main evolutionary entities. Based on the whole process idea, the key entities are extracted from the aspects of system guarantee level, technical support level and the three process of energy planning, investment construction, operation and maintenance. The relationship between the main body and the main body of the distributed energy system in the initial stage is shown in Figure 5.

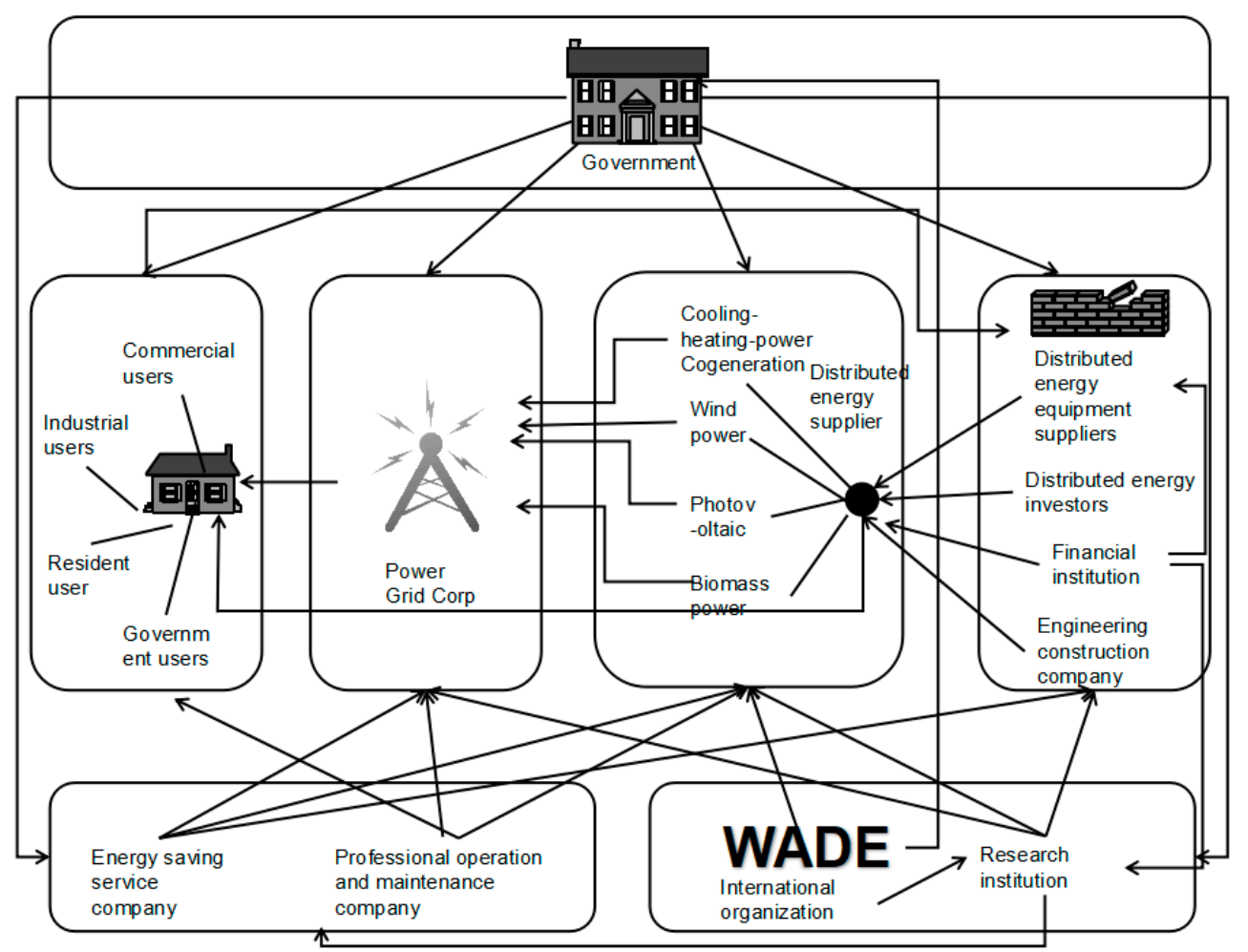

Figure 5. Schematic diagram of the main body relationship of the distributed energy system in the initial stage.

The relationship between the main body and the main body of the distributed energy system in the promotion stage is shown in Figure 6. 


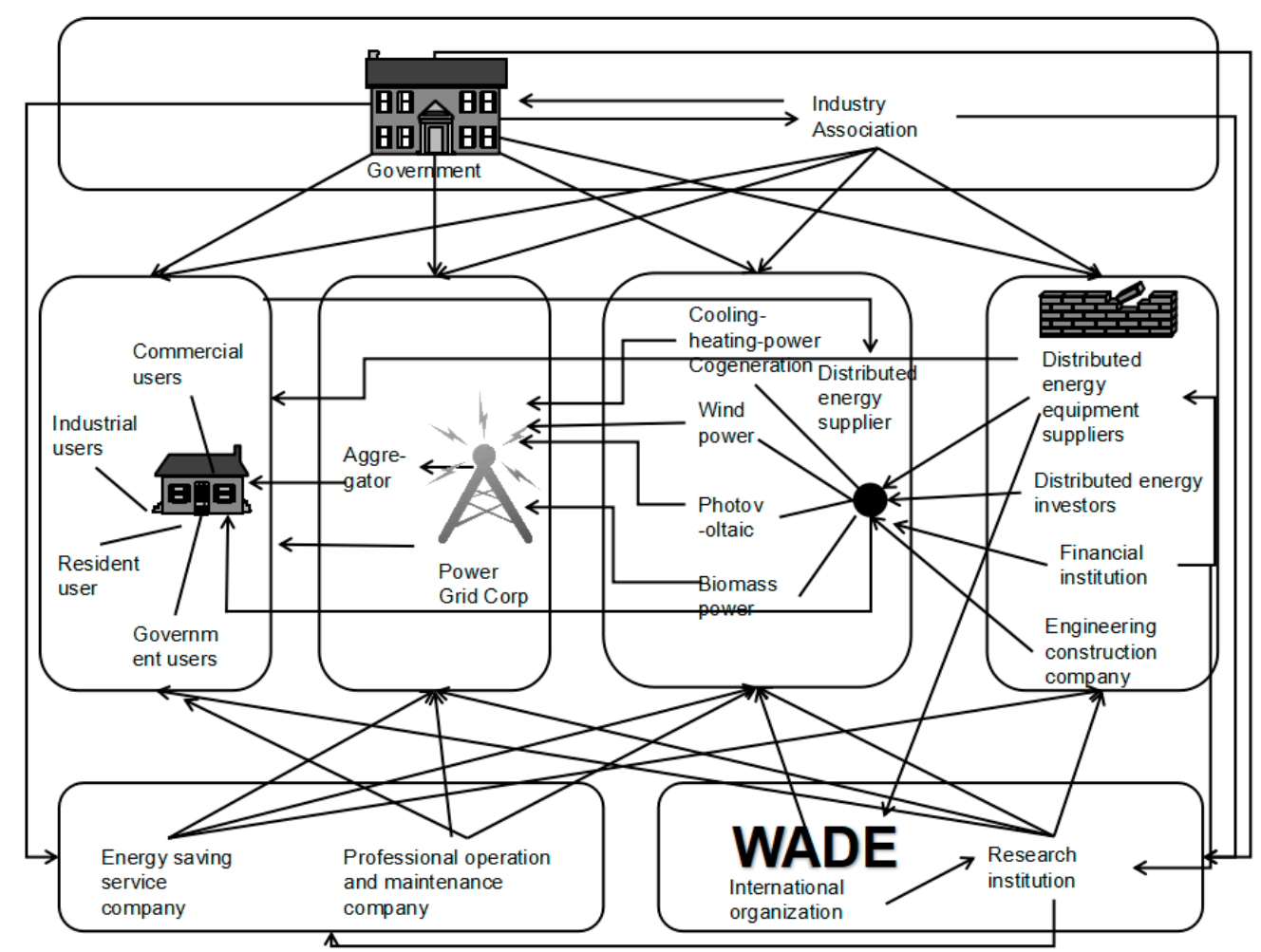

Figure 6. Schematic diagram of the main body relationship of the distributed energy system in the promotion stage.

According to the two-stage association diagram and the power-related experts' review, the study constructs the main energy relationship matrix of the distributed energy system. The degree of association between the participating entities presents different degrees of strength, and the relationship matrix between distributed energy subjects is as listed in Tables 2 and 3. Each column in the table represents the associated behavior accepted by the entity. Each row represents the associated behavior of the synergetic entities. The letters in the matrix indicate the type of association. The numbers in the matrix indicate the strength of the association. Level 1 indicates weak contact, level 2 indicates general contact, 3 indicates strong contact; $P$ indicates policy management, $C$ indicates capital flow, $\mathrm{I}$ indicates public opinion impact, $\mathrm{E}$ indicates basic attribute, $\mathrm{T}$ indicates technical support, and $\mathrm{R}$ indicates technology research and development.

Table 2. The multi-agent relationship matrix of the initial stage of the distributed energy system.

\begin{tabular}{|c|c|c|c|c|c|c|c|c|c|c|c|c|}
\hline Main Body & A & D & F & G & H & $\mathbf{J}$ & K & $\mathbf{M}$ & $\mathbf{N}$ & O & Q & $\mathrm{S}$ \\
\hline A & & P2 & P3 & P2 & P2 & P3 & P3 & P2 & P2 & & P2 & $\mathrm{P} 2$ \\
\hline D & & & & & & T3 & & & & & & \\
\hline F & & & & & & C3 & & & & & & \\
\hline G & & $\mathrm{C} 1$ & & & & C3 & & & C2 & & & \\
\hline $\mathrm{H}$ & & & & & & T3 & & & & & & \\
\hline $\mathrm{J}$ & & & & & & & E2 & E3 & & & & \\
\hline $\mathrm{K}$ & & & & & & & & E3 & & & & \\
\hline $\mathrm{M}$ & & & & & & C3 & & & & & & \\
\hline $\mathrm{N}$ & & & & & R1 & R2 & R1 & R2 & & & R1 & R1 \\
\hline $\mathrm{O}$ & I1 & & & & & I2 & & & I1 & & & \\
\hline $\mathrm{Q}$ & & & & & $\mathrm{T} 2$ & T2 & $\mathrm{T} 2$ & & & & & \\
\hline$\hat{\mathrm{S}}$ & & & & & & $\mathrm{T} 2$ & $\mathrm{~T} 2$ & $\mathrm{~T} 1$ & & & & \\
\hline
\end{tabular}


Table 3. The multi-agent relationship matrix of the promotion stage of the distributed energy system.

\begin{tabular}{|c|c|c|c|c|c|c|c|c|c|c|c|c|c|c|}
\hline Main Body & $\mathbf{A}$ & B & D & F & G & $\mathbf{H}$ & $\mathbf{J}$ & $\mathbf{K}$ & L & $\mathbf{M}$ & $\mathbf{N}$ & $\mathrm{O}$ & $\mathbf{Q}$ & $S$ \\
\hline A & & P2 & P3 & P2 & P2 & P2 & P3 & P3 & P2 & P2 & P3 & & P2 & P2 \\
\hline B & $\mathrm{I} 2$ & & & $\mathrm{I} 2$ & $\mathrm{I} 2$ & I2 & I3 & $\mathrm{I} 2$ & $\mathrm{I} 2$ & $\mathrm{I} 2$ & I2 & & & \\
\hline $\mathrm{D}$ & & & & & & & T3 & & & & & & & \\
\hline $\mathrm{F}$ & & & & & & & C3 & & & & & & & \\
\hline G & & & C1 & & & & C3 & & & & C3 & & & \\
\hline $\mathrm{H}$ & & & & & & & T3 & & & & & & & \\
\hline $\mathrm{J}$ & & & & & & & & E2 & & E3 & & I2 & & \\
\hline $\mathrm{K}$ & & & & & & & & & E3 & E3 & & & & \\
\hline $\mathrm{L}$ & & & & & & & & & & E3 & & & & \\
\hline M & & & & & & & C3 & & & & & & & \\
\hline $\mathrm{N}$ & & & & & & $\mathrm{R} 2$ & R3 & $\mathrm{R} 2$ & R2 & R3 & & & $\mathrm{R} 2$ & $\mathrm{R} 2$ \\
\hline $\mathrm{O}$ & $\mathrm{I} 2$ & I2 & & & & & $\mathrm{I} 2$ & & & & I3 & & & \\
\hline $\mathrm{Q}$ & & & & & & $\mathrm{T} 2$ & $\mathrm{~T} 2$ & $\mathrm{~T} 2$ & & & & & & \\
\hline$\widehat{S}$ & & & & & & & $\mathrm{~T} 3$ & $\mathrm{~T} 2$ & $\mathrm{~T} 1$ & $\mathrm{~T} 1$ & & & & \\
\hline
\end{tabular}

In Tables 2 and 3, A = Government, B = Industry Association, D = Distributed energy equipment supplier, F = Distributed energy investor, $\mathrm{G}=$ Financial Institutions, $\mathrm{H}=$ Engineering construction company, $\mathrm{J}=$ Distributed energy supplier, $\mathrm{K}=$ Grid company, $\mathrm{L}=$ Aggregator, $\mathrm{M}=$ User, $\mathrm{N}=$ Research institutions, $\mathrm{O}=$ International organizations, $\mathrm{Q}=$ Energy service company, $\mathrm{S}=$ Professional operation and maintenance company.

\subsection{Synergistic Entropy Construction}

Entropy is one of the parameters that characterize the state of matter in thermodynamics. Its physical significance is to measure the degree of chaos of the system. In this paper, synergy entropy is used to evaluate the multi-agent synergy of distributed energy systems. The aim is to construct an effective index to measure the synergy effect of the complex multi-agent network of the whole distributed energy system. Synergistic entropy is better for dynamic evaluation than traditional methods. The calculation results can show the development trend, find the optimization direction and the sustainable development path.As a quantitative analysis method for dissipative structures, the Brusselator model also provides a theoretical basis and an operational mathematical model for studying the related problems of distributed energy system coordination. In this paper, it is applied to the synergistic analysis of distributed energy systems. Based on the existing research results, the original Brusselator model is transformed, that is, the significance represented by A, B, D, E, X and Y is transformed into the related concept of distributed energy system coevolution.

Let $\mathrm{A}$ and $\mathrm{B}$ be the components of the cooperative energy entropy of the distributed energy system, that is, A is the positive entropy generated by the synergistic participant, and B is the negative entropy formed by the synergistic participant accepting the related association behavior. D and E are A. Two possible states under the interaction with B: D is the state of non-dissipative structure, that is, the group relationship of each synergistic participant is not clear; $\mathrm{E}$ is the state of dissipative structure, that is, the group relationship of each synergistic participant is clear. X, Y are quantifiable indicators that affect the degree of clarity of synergistic participation subject relationships, where $X$ represents a quantifiable positive entropy indicator and $Y$ represents a quantifiable negative entropy indicator. Based on the above definition, this study constructs a Brusselator model of distributed energy system coordination, as shown in Equation (1):

$$
\mathrm{A}(\text { Positive entropy }) \stackrel{K 1}{\rightarrow} \mathrm{X} \text { (A quantifiable positive entropy indicator) }
$$

$\mathrm{B}$ (Negative entropy $)+\mathrm{X} \stackrel{K 2}{\rightarrow} \mathrm{Y}(\mathrm{A}$ quantifiable negative entropy indicator $)+\mathrm{D}$ (Non dissipative structure $)$

$$
\begin{gathered}
2 \mathrm{X}+\mathrm{Y} \stackrel{K 3}{\rightarrow} 3 \mathrm{X} \\
\mathrm{X} \stackrel{K 4}{\rightarrow} \mathrm{E}(\text { Dissipative structure) }
\end{gathered}
$$


The study uses the synergetic entropy of the distributed energy system to represent that the distributed energy system participates in the synergistic main body and the factors affecting the synergy. In the synergistic process, the effective energy conversion efficiency decreases, and the ineffective energy consumption increases. System status coefficient changes. According to the characteristics of the entropy value, in the synergistic process of distributed energy systems, the larger the synergistic entropy value, the worse the synergistic evolution effect between entities; on the contrary, the better the synergistic evolution between entities.

Claude E. Shannon, one of the originators of information theory, expresses multiple discrete events in system $S$ as discrete event sets. $S=\left\{E_{1}, E_{2}, \cdots, E_{n}\right\}$, where the probability of each event appearing randomly is $P=\left\{P_{1}, P_{2}, \cdots, P_{n}\right\}$, so information entropy (i.e. total amount of information) can be defined as Equation (2):

$$
H(S)=-\sum P_{i} \log P_{i}, i=1,2, \cdots, n
$$

Based on the above-mentioned distributed energy system synergistic Brusselator model structure (Equation 1), this study assumes that in the synergistic process of distributed energy systems, $f_{i}$ is the number of the paths that the $i$ participating synergistic entity points to the other. $f_{i}^{\prime}$ is the number of synergy paths for the $i$ participants to accept other synergistic participants. Assuming that there are " $n$ " co-participants in the distributed energy system, the total number of co-evolution paths of the distributed energy system is as follows:

$$
f=\sum\left(f_{i}+f_{i}^{\prime}\right),(i=1,2, \cdots, n)
$$

In this article, we write $P$ as $P=\frac{\left(f_{i}-f_{i}^{\prime}\right)}{f}$.According to the relationship between probability and Shannon's entropy function, the evolutionary cooperative entropy expression of distributed energy systems can be obtained:

$$
C E_{i}=-\sum P_{i} \times \log \left|P_{i}\right|,(i=1,2, \cdots, n)
$$

\subsection{Synergetic Entropy Analysis of Distributed Energy Systems}

According to the contents of Equations (4) and Tables 2 and 3, the out-degree value and in-degree value of each evolutionary participant and the total number of relationships associated with it in the distributed energy system are calculated. In short, taking participant $A$ as an example, the out-degree value is the number of the relationship lines that the participant participates in the remaining participants. The in-degree value is the number of association lines that the participant accepts from other participants. The number of all associations is the sum of their out-degree and in-degree value. The evolutionary cooperative entropy value of each synergistic participant is determined by the difference between the in-degree and out-degree value and the ratio of overall relationship.

According to the above introduction, the cooperative entropy value of each participating entity in the two stages of the distributed energy system is calculated. The evolutionary cooperative entropy includes positive entropy and negative entropy. Positive entropy will generate system internal friction and increase system evolution burden. Conversely, negative entropy will neutralize the system internal friction and coordinate the evolution of the overall system; The larger the entropy value, the worse the synergy performance of the subject. The larger the negative entropy value, the better the synergy performance of the subject. Figure 7 shows in detail the changes in entropy values of distributed energy systematization participants (presenting positive entropy or negative entropy). According to the data provided in Figure 7, the change rule of the entropy value of each participant and the co-evolution effect of each stage are analyzed.Because the weight establishment process of each synergistic participant is complex, there are many driving factorsand the data collection is very difficult, this study only performs the simple addition of the entropy values of the participants in the same level. 


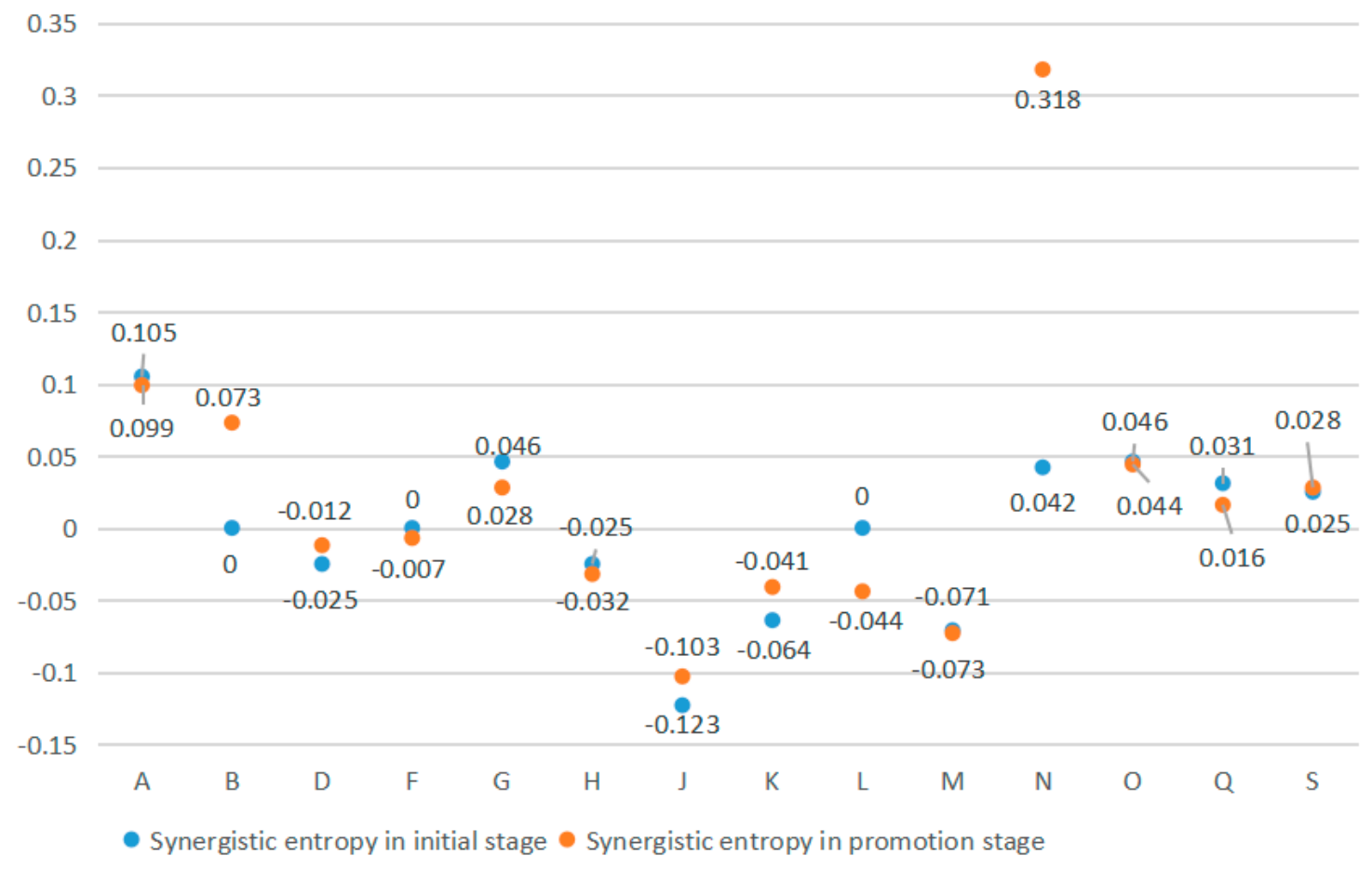

Figure 7. Distributed energy system cooperative entropy results. $A=$ Government, $B=$ Industry Association, $\mathrm{D}=$ Distributed energy equipment supplier, $\mathrm{F}=$ Distributed energy investor, $\mathrm{G}=$ Financial Institutions, $\mathrm{H}$ = Engineering construction company, J = Distributed energy supplier, $\mathrm{K}=$ Grid company, $\mathrm{L}=$ Aggregator, $\mathrm{M}=$ User, $\mathrm{N}=$ Research institutions, $\mathrm{O}=$ International organizations, $\mathrm{Q}=$ Energy service company, $\mathrm{S}=$ Professional operation and maintenance company.

Through the statistical analysis of the synergistic entropy values of the synergistic entities of the distributed energy system, this paper concludes the following: Among the 14 participants, engineering construction companies, distributed energy suppliers, distributed energy equipment suppliers, power grid companies, and users all maintain negative entropy values in both phases. Among them, the entropy value of the grid company changed from -0.064 to -0.041 , the largest change, indicating that the coordination degree of the grid company is significantly improved during the promotion stage. This change is due to the serious implementation of the national energy development strategy by power grid enterprises under the background of policy promotion and the China's electricity reform policy. The grid company began to participate in distributed energy operations, and promoted the development of new energy and distributed power as an important political responsibility and social responsibility, and actively served the distributed energy system. The aggregator is a new type of participant between the user and the grid company. It appears for the first time in the promotion stage, with an entropy value of -0.044 . As a participant in the power market operation, aggregators can not only buy electricity from the grid or users, but also sell their own stored power to users or power grids, with better synergy. The synergistic entropy of users changed from -0.071 to -0.073 , and the synergistic ability fluctuated slightly. This is possibly due to the fact residential users began to install their own small-scale distributed energy at the promotion stage. All aspects of policy conditions are uncertain, leading to the degree of synergy appear a slight decline. The entropy values of engineering construction companies and distributed energy suppliers have not changed much, and the overall coordination situation is good.

The cooperative entropy values of government departments, industry associations, financial institutions, scientific research institutions, international organizations, and energy conservation service companies are all positive entropy values. Among them, the entropy value of international organizations has declined by a large margin, indicating that its influence is gradually increasing. This change is attributed to the increasing emphasis on the coordinated development of distributed 
energy systems by international organizations, which have enacted global energy policies such as the 2030 Agenda for Sustainable Development, promulgated in 2016. All countries recognize the government plays an important role in supporting power system transformation and energy system integration, and will cooperate to promote technology development and deployment in the fields of energy storage, electric vehicles and modern biomass energy, renewable energy heating, etc.,cooperate in accelerating smart grid deployment and interoperability. These policies not only provide a framework for the development of distributed energy systems in various countries, but also provide external pressure for the coordination of distributed energy systems from the perspective of international supervision. The synergy entropy of the government departments is positive and the change is not sigificant, indicating that the government's policies on distributed energy systems are not in place. At this stage, there is still a lack of technical standards and management standards at the national level.

\subsection{Comprehensive Benefits Improvement Strategy of Distributed Energy System}

Combined with the characteristics of distributed energy, the influencing factors of comprehensive benefits and the current synergy between various entities, guided by the sustainable development of distributed energy, this paper proposes a comprehensive benefits and multi-agent synergistic optimization strategy for distributed energy systems.

\subsubsection{Synergistic Optimization Strategies of Comprehensive Benefits of Government-Side}

The optimization of the government side is based on the system construction of the comprehensive energy system. Through the formulation of relevant policies and laws and regulations, the cooperation with distributed energy system and scientific research institutions should be strengthened to standardize the development of distributed energy. The development level and comprehensive benefits of distributed energy should be further improved by relying on the demonstration and promotion led by the government. Specific synergistic optimization strategies are as follows.

(1) Improve the participation at the national macro level in the multi-agent synergy of distributed energy systems. Government should co-ordinate management andlegally regulate distributed generation and energy utilization models. Meanwhile, establish a national energy comprehensive management function department that adapts to the national conditions, and formulate relevant laws and regulations on distributed power sources, and clearly define distributed energy in law; establish an integrated energy research and development institution, conduct research on major issues in the energy field, and coordinate energy long-term planning to facilitate cooperation, integration and synergetic development in the energy field.

(2) Government should continue to issue clear policy signals, provide a flexible policy environment, further clarify the development orientation of distributed energy in energy transformation, increase financial support and tax support, subsidize project construction, especially the construction of demonstration projects, and consider returning part of the value added tax. At the same time, the power price compensation mechanism shall be improved and price concessions shall be implemented to coordinate the interests of different energy supply participants. In the mean time, further refine the overall objectives and main technical indicators of distributed energy development, and provide favorable grid-connected conditions, focus on the planning of distributed energy projects, and clarify the application conditions and approval procedures. Increase the supervision of key links such as grid connection and transaction after the completion of the project.

(3) Strengthen the coordination of distributed energy market, explore the adapted trading mode of distributed energy, and promote the distributed new energy microgrid in combination with the requirements of the power system, to make the microgrid into a market entity with independent power sales rights, including the distributed energy microgrid carrier as an independent power selling entity, for direct PV supply or interaction with nearby new energy projects. Encourage grid companies to give preferential treatment to internal and external transactions of distributed energy. At the same 
time, all power and energy companies are encouraged to actively participate in the construction of distributed energy projects, and arouse the enthusiasm of local capital to participate in the project to achieve win-win cooperation and benefits sharing.

(4) Enhance the degree of synergy with scientific research institutions and international organizations. The government should respond positively to the call of international organizations and integrate with the world goals. According to the future development direction, increase investment in scientific research, and propose to set up special funds for research on distributed energy technologies to cultivate professional talents. For instance, to train professional distributed energy planners. These talents must be familiar with relevant policies and regulations, understand various related technologies, and select appropriate distributed technologies according to local climate conditions and resources to achieve the best comprehensive benefits. Leaders in various energy sectors should take the lead in conducting distributed energy knowledge and technical training, enabling professionals to take the decision-making role and correctly guide the direction of distributed energy development.

\subsubsection{Synergistic Optimization Strategies of Comprehensive Benefits of Distributed Energy Systems}

The synergistic optimization of power side mainly consists of three aspects: energy planning, location valuation, capacity and equipment optimization. The specific optimization strategy is as follows:

(1) Energy service companies and aggregators should continuously build their core competitiveness, effectively integrate the resources of the industry chain, so that the benefits can bring together the entire industry chain and promote the synergetic development of the entire industry. In the early stage of energy planning, the planned system scope and energy load should be carefully considered, the basic types of projects should be clarified, and the development of distributed energy resources should be strengthened. Focusing on existing and future planned gas turbine power plants, the distributed energy project is developed in the controllable area of gas turbine power plants, which take advantage of the power generation and heat supply stability of the gas turbine power plant to ensure the continuous and stable operation of the system and enhance the reliability of the system operation. Actively plan integrated distributed energy supply solutions for natural gas, solar energy, wind energy, geothermal energy, biomass energy and energy storage to create an efficient and integrated energy supply model.

(2) Installing a distributed power source of appropriate capacity at a suitable location can reduce network loss and improve power quality. Methods for determining the optimal capacity and location should be explored to maximize the benefits of loss reduction. The power-side can consider actively investing in distributed energy projects in the demonstration area to strive for optimal policy support. In other areas where there is a high-quality load, a selective development project can be considered.

(3) Optimize the type and quantity of integrated energy system supply and storage equipment. Based on the overall load level of integrated energy in the planning area, the optimal combination scheme of refrigeration, heating, cooling and heat storage devices in the planning area is proposed for a variety of optimal planning objectives and the optimal operation of the whole life cycle. Secondly, the operation scheduling of the integrated energy system equipment should be optimized, and the system operation constraints and supply and demand balance constraints of energy supply and storage equipment are considered under different energy demand periods. Under the guidance of supply-demand relationship and price mechanism, various participants flexibly adjust energy supply, energy consumption and energy storage to achieve flexible interaction of integrated energy and vertical integration of supply-demand and storage, and improve the utilization efficiency of integrated energy.

\subsubsection{Synergistic Optimization Strategies of Comprehensive Benefits of Power Grid Company}

The optimization strategy of the power grid is based on the synergy enthusiasm of power grid enterprises. Under the condition of upgrading key technologies, coordinated planning and operation are carried out, and the pilot project is built on the premise. The specific optimization strategy is as follows: 
(1) Power grid companies should consciously and actively improve the degree of synergy. Under the background of the reform of electric power, power grid enterprises have the right and obligation to actively participate in the investment, construction, operation and management of distributed energy projects, and realize the dual role mechanism transformation of distributed energy stakeholders. On the one hand, in order to avoid conflicts with the provisions of the Electricity Law, grid power companies can be used as stakeholders or project shareholders of distributed energy projects, and members of distributed energy are represented as legal representatives. On the other hand, the distributed energy enterprise thus formed can be used as a member of the power grid enterprise. Under the premise of meeting the terminal demand in the distributed energy region, according to the characteristics of the supply and demand balance of the large power grid and the function of the smart grid, the distributed generation unit's opening, stopping and load rate are adjusted and optimized to realize the switching between the two modes of operation: grid power or online power sale during peak and low valley periods.

(2) Strengthen coordination with scientific research institutions, study key technologies of distributed energy, increase independent research and development efforts, and reduce dependence on technology in developed countries. In the future, we should further study the protection and control technologies of distributed energy and the new protection principles and methods of distributed power systems to improve the security of the entire social energy supply system. Grid company should analyze the operating characteristics of various distributed power sources and microgrids, the interaction mechanism between distributed power sources, microgrids, and power distribution systems. Developing relevant theories and methods, laying the foundation for energy management and distributed generation economic dispatch. It is necessary to research on distributed power grid-connected technology for the purpose of achieving efficient and user-friendly grid-connected power generation.

(3) Research on coordinated planning methods for distributed power distribution systems. Consider establishing a distribution network design and planning theory system suitable for distributed power supply characteristics, including distribution system structure design methods that contribute to microgrid access, comprehensive performance evaluation index system including distributed energy distribution systems, and new power distribution System optimization planning theory, etc.

\subsubsection{Synergistic Optimization Strategies of Comprehensive Benefits of User-Side}

The user-side synergistic optimization strategy is optimized through market demand response and user-side construction. The specific strategies are as follows:

(1) Strengthen the synergy among the government, financial institution and the user, liberalize the user-side distributed power supply construction, and promote the operation mode of "spontaneous use, surplus Internet access, and power grid adjustment" to encourage enterprises, institutions, communities, and families to adjust their own conditions. Invest in the construction of various types of distributed power sources such as rooftop solar and wind energy. It can integrate many small-scale energy comprehensive utilization equipment with different forms. In addition to the traditional electric/heat/cold load, it also includes a large number of renewable energy equipment, energy storage equipment, and comprehensive energy supply equipment.

(2) Apply the energy management system on the user side to guide users to avoid the peak of power consumption and cultivate better user habits. Improve the flexibility and reliability of power supply, give priority to the use of local renewable energy or large grid through power, and encouraging new energy sources to access the power demand side management platform in the region. The energy management department should work with relevant departments to study and formulate the demand side management policy of the distributed energy source, and explore the establishment of distributed energy as a market entity to participate in service compensation mechanisms such as interruptible load peak shaving, electric energy storage peak shaving, and black starts. 
(3) Increase cooperation with scientific research institutions, use the energy Internet, integrate user-side services, smart grids and distributed generation, and develop smart electricity interactive business models and intelligent power system frameworks. And consider the energy characteristics of equipment for home users and business users, and develop intelligent power technology that integrates information collection, energy efficiency assessment, equipment control, and two-way interaction to realize household energy safety monitoring, electricity consumption information and property management. Function to integrate intelligent microgrid technology with distributed energy. In terms of terminal hardware, a user-oriented intelligent interactive terminal core module shall be developed to realize energy metering and device monitoring for large-scale users.

\section{Conclusions}

Based on China's energy structure, this paper focuses on the development of distributed energy. Through synergistic entropy evaluation, under the guidance of system dynamics, the comprehensive benefits of distributed energy at the present stage are analyzed. By using synergy entropy concept, the synergy degree among different agents are evaluated, and the path of improving comprehensive benefits of distributed energy through synergistic optimization is found from the multi-agent level of government, power supply, power grid and users, and draw the following research conclusions:

The analysis of this paper concludes that the improvement of the comprehensive benefits of distributed energy depends on the government's policy support, the user's main needs, and the degree of synergy between the various entities. From these factors, the comprehensive benefits can be improved. Through literature analysis, a three-level indicator for measuring comprehensive benefits is proposed. Through case analysis, it is concluded that the further improvement of the comprehensive benefits of distributed energy depends on the improvement of the coordination among the main bodies. Through synergistic entropy calculation, the synergy of Power Grid Corp and distributed energy is increased fastest. The synergy of government departments, trade associations, financial institutions, scientific research institutions, international organizations and energy-saving service companies needs to be strengthened. And from the multi-agent optimization synergy level, the comprehensive benefit enhancement strategy is put forward.

In the future, distributed energy can strengthen multi-agent cooperation in government system construction, policy promulgation, demonstration and promotion, power side planning and location, equipment optimization, grid side improving technology, coordinated planning and construction pilot projects, user-side energy optimization and user-side construction, so as to improve comprehensive benefits and utilization level in an all-round way and promote the coordinated development of multi-agent and the transformation and upgrading of the energy structure.

Author Contributions: Conceptualization, X.S. and J.L.; Data curation, M.S.; Investigation, M.S.; Methodology, M.S. and Y.W.; Supervision, X.S. and J.L.; Writing-original draft, M.S.; Writing-review \& editing, X.S., M.S., Y.W. and J.L.

Funding: This study is supported by the National Natural Science Foundation of China (NSFC) (71501071), Beijing Social Science Fund (16YJC064,17GLB010) and the Fundamental Research Funds for the Central Universities (2018ZD14,2017MS059).

Conflicts of Interest: The authors declare no conflict of interest.

\section{References}

1. Di Somma, M.; Graditi, G.; Heydarian-Forushani, E. Stochastic optimal scheduling of distributed energy resources with renewables considering economic and environmental aspects. Renew. Energy 2018, 116, 272-287. [CrossRef]

2. Chen, B.; Lin, S.P. Develop Distributed Energy to Promote the Energy Conservation and Emission Reduction of the State. In Second China Energy Scientist Forum 2010; Scientific Research Publishing Inc.: Xuzhou, China, 2010. 
3. Niu, C.H.; Li, B.J. Research on the Technical and Economic Problems of the Development of Distributed Generation. In Proceedings of the International Conference on Logistics Engineering, Management and Computer Science (LEMCS), Shenyang, China, 29-31 July 2015.

4. Kim, H.M.; Kinoshita, T. A New Challenge of Microgrid Operation. In Proceedings of the 1st International Conference on Security-Enriched Urban Computing and Smart Grid, Daejeon, Korea, 15-17 September 2010.

5. Zeng, M.; Ouyang, S.J.; Shi, H.; Ge, Y.J.; Qian, Q. Overall review of distributed energy development in China: Status quo, barriers and solutions. Renew. Sustain. Energy Rev. 2015, 10, 1226-1238. [CrossRef]

6. Serrano, J.X.; Escriva, G. Simulation Model for Energy Integration of Distributed Resources in Buildings. IEEE Lat. Am. Trans. 2015, 13, 166-171.

7. Omu, A.; Rysanek, A.; Stettler, M.; Choudhary, R. Economic, Climate Change, and Air Quality Analysis of Distributed Energy Resource Systems. Procedia Comput. Sci. 2015, 51, 2147-2156. [CrossRef]

8. Inamori, J.; Nonogaki, M.; Hirose, K. Cost-benefit Analysis of a Microgrid System. In Proceedings of the IEEE International Telecommunications Energy Conference (INTELEC), Osaka, Japan, 18-22 Octber 2015.

9. Zhang, Z.; Li, G.Y.; Zhou, M. Application of Microgrid in Distributed Generation Together with the Benefit Research. In Proceedings of the IEEE PES General Meeting, Minneapolis, MN, USA, 25-29 July 2010.

10. Di Somma, M.; Yan, B.; Bianco, N.; Graditi, G.; Luh, P.B.; Mongibello, L.; Naso, V. Operation optimization of a distributed energy system considering energy costs and exergy efficiency. Energy Convers. Manag. 2015, 103, 739-751. [CrossRef]

11. He, Y.X.; Xu, Y.; Xia, T.; Zhang, J.X. Business Impact and Policy on the Major Players in the Market of the Development of Distributed Energy in China. Math. Prob. Eng. 2016, 10. [CrossRef]

12. Zhang, L.; Chen, X.Y.; Chen, K.; Ding, X.H.; Chen, X.Y.; Liao, Y.C.; Yu, K. Coordinated Control Strategy of Distributed Photovoltaic Generation and Load. Appl. Mech. Mater. 2014, 457-458, 1266-1271. [CrossRef]

13. Li, M.J.; Yan, J.Y.; Lu, T.Q.; Liu, S.N.; Liu, T.; Li, D.X. Research on Distribution Network Comprehensive Integration Technology in Micro-Grid. In Proceedings of the International Conference on Sensing, Diagnostics, Prognostics, and Control (SDPC), Shanghai, China, 16-18 August 2017.

14. Reinders, A.; de Respinis, M.; van Loon, J.; Stekelenburg, A.; Bliek, F.; Schram, W.; van Sark, W.; Esterl, T.; Uebermasser, S.; Lehfuss, F. Co-evolution of smart energy products and services: A novel approach towards smart grids. In Proceedings of the Asian Conference on Energy, Power and Transportation Electrification (ACEPT), Singapore, 25-27 October 2016.

15. Bale, C.S.; Varga, L.; Foxon, T.J. Energy and complexity: New ways forward. Appl. Energy 2015, 138, 150-159. [CrossRef]

16. Han, Z.H.; Qi, C.; Xiang, P.; Liu, M.H.; Wang, S. Benefit analysis and comprehensive evaluation of distributed energy system. Therm. Power Gener. 2018, 2, 31-36. [CrossRef]

17. Dong, F.G.; Zhang, Y.; Shang, M.M. Research on multi index comprehensive evaluation of distributed energy system. Proc. CSEE. 2016, 12, 3214-3223. [CrossRef]

18. Zeng, M.; Xie, B.; Yan, B.J.; Lin, X.; Zhang, Y.N.; Xue, S. Comprehensive benefits evaluation of micro network based on multi factor analysis. Water Res. Power 2013, 31, 247-249, 256. (In Chinese)

19. He, J.; Zhou, K.P.; Xin, J.H.; Chen, K.; Deng, C.H. New Metrics for Assessing Fuel Price and Technological Uncertainty in Microgrid Power Planning. In Proceedings of the 10th IEEE Conference on Industrial Electronics and Applications, Auckland, New Zealand, 15-17 June 2015.

20. Wu, H.B.; Liu, X.Y.; Ding, M. Dynamic economic dispatch of a microgrid: Mathematical models and solution algorithm. Int. J. Electr. Power Energy Syst. 2014, 63, 336-346. [CrossRef]

21. Xie, X.; Cao, Y.; Yuan, Y.; Guo, S.Q. Benefit analysis of energy saving and emission reduction for micro grid diesel engine based on ladder peak valley tariff. Autom. Electr. Power Syst. 2014, 8, 1-6.

22. Chen, B.S.; Liao, Q.F.; Liu, D.C.; Wang, W.Y.; Wang, Z.Y.; Chen, S.Y. Comprehensive evaluation index and method of regional integrated energy system. Autom. Electr. Power Syst. 2018, 4, 174-182.

23. Liang, H.S.; Cheng, L.; Su, J. Cost-benefit analysis of microgrid. Proc. CSEE 2011, S1, 38-44. [CrossRef]

24. Zhang, T.; Zhu, T.; Gao, N.P.; Wu, Z. Research on optimal design and multi index comprehensive evaluation method of distributed thermoelectric energy system. Proc. CSEE 2015, 14, 3706-3713. [CrossRef]

25. Zeng, C.H. Analysis on environmental benefits and environmental problems of distributed energy planning in a certain area of Beijing. J. Shenyang Inst. Eng. Nat. Sci. 2014, 4, 305-308. [CrossRef] 
26. Xu, X.F.; Mitra, J.; Wang, T.T.; Mu, L.H. Reliability Evaluation of a Microgrid Considering its Operating Condition. J. Electr. Eng. Technol. 2016, 11, 47-54. [CrossRef]

27. Gludpetch, S.; Tayjasanant, T. Optimal Placement of Protective Devices For Improving Reliability Indices in Microgrid System. In Proceedings of the IEEE PES Asia-Pacific Power and Energy Engineering Conference (APPEEC), Kowloon, China, 8-11 December 2013.

28. Tian, S.X.; Cheng, H.Z.; Chang, H.; Qi, Q.R.; Liu, L.; Hong, S.Y. Social benefit analysis and evaluation method of UHV power grid. Electr. Power Autom. Equip. 2015, 35, 145-153. [CrossRef] 